\title{
Capitanes a Guerra: Gobierno económico y político en el Virreinato del Nuevo Reino de Granada*
}

\begin{abstract}
Jorge Conde Calderón
Docente de la Universidad del Atlántico (Colombia). Correo electrónico: jorgecondecalderón@gmail.com. El autor es magister en Historia de la Universidad Nacional de Colombia, sede Bogotá (Colombia) y doctor en Historia de América Latina de la Universidad Pablo de Olavide (España). Codirector del Grupo de Investigaciones Históricas en Educación e Identidad Nacional (Categoría A, Colciencias), grupo interinstitucional de la Universidad del Atlántico (Colombia), Universidad de Caldas (Colombia) y Universidad de Tolima (Colombia). Entre sus publicaciones recientes tenemos: "La administración de Justicia en las sociedades rurales del Nuevo Reino de Granada, 1739-1803” en Historia Crítica Vol. 49 (2013) y “La conversión de milicianos y guerrilleros en ciudadanos armados de la República de Colombia" en Historia Caribe Vol. IX, No. 25 (2014). Entre sus temas de interés están La ciudadania y clase en el Caribe colombiano, 1821-1855.
\end{abstract}

Recibido: 13 de febrero de 2016

Aprobado: 12 de abril de 2016

Modificado: 15 de mayo de 2016

Artículo de investigación científica

DOI: http://dx.doi.org/10.15648/hc.29.2016.7

* Este artículo corresponde a los antecedentes históricos del proyecto: "Poderes locales, configuración regional y legitimidad política en el Caribe colombiano, 1991-2010" financiado por la Universidad del Atlántico (Colombia).

Esta publicación está bajo una licencia Creative Commons Reconocimiento-NoComercial 4.0. 
Capitanes a Guerra: Gobierno económico y político en el Virreinato del Nuevo Reino de Granada

\title{
Resumen
}

Los Capitanes a Guerra constituyeron un caso de gobernantes, empleados según las peculiaridades provinciales del virreinato del Nuevo Reino de Granada. El presente artículo examina sus actuaciones dentro del marco legal e institucional en el cual surgieron y se legitimaron. De igual manera, examina sus nombramientos en el gobierno económico y político de algunas ciudades, villas, sitios y partidos del virreinato como un elemento articulado a una política de Estado. Finalmente, estudia algunos conflictos jurisdiccionales que sostuvieron contra gobernadores y otros jueces, y las disputas recurrentes con los vecinos por las acciones tomadas como administradores de justicia y del gobierno de la república.

Palabras clave: Capitanes a Guerra, ciudades, villas, sitios, gobierno de la justicia.

Captains of War: Economic and Political Governance in the Viceroyalty of the Kingdom of Nueva Granada

\begin{abstract}
Captains of War constituted a case of governors, employees according to provincial peculiarities of the Viceroyalty of Nueva Granada. This paper examines their actions within the legal and institutional framework in which they emerged and legitimated. Likewise, it examines their appointments in the economic and political governance of some cities, towns, places and parties of the viceroyalty as an articulated state policy element. Finally, it studies some jurisdictional conflicts they held against governors and other judges, and recurrent disputes with neighbors due to actions taken as managers of justice and government of the republic.
\end{abstract}

Key words: Captains of War, cities, towns, places, department of Justice.

Capitães a Guerra: Governo econômico e político no Virreinato do Novo Reino de Granada

\section{Resumo}

Os Capitães a Guerra constituíram um caso de governantes, empregados segundo as 
peculiaridade provinciais do virreinato do Novo Reino de Granada. O presente artigo examina suas atuações dentro do marco legal e institucional no qual surgiram e se legitimaron. Do mesmo modo, examina suas nomeações no governo econômico e político de algumas cidades, villas, lugares e partidos do virreinato como um elemento articulado a uma política de Estado. Finalmente, estuda alguns conflitos jurisdicionais que sustentaram contra governadores e outros juízes, e as disputas recorrentes com os vizinhos pelas ações tomadas como administradores de justiça e do governo da república.

Palavras-chave: Capitães a Guerra, cidades, villas, lugares, governo da justiça.

Des capitaines à Guerre: Gouvernement économique et politique dans la vice-royauté du Nouveau Royaume de Grenade

\section{Résumé}

Les Capitaines à Guerre constituèrent un cas de gouverneurs, employés selon les particularités des provinces de la vice-royauté du Nouveau Royaume de Grenade. Cet article examine leurs actions dans le cadre légal et institutionnel dans lequel ils ont apparu et se sont légitimés. De même, il examine leur désignation dans le gouvernement économique et politique de quelques villes, villages, site et partis de la vice-royauté en tant qu'élément articulé à une politique d'État. Finalement, il étudie quelques conflits juridictionnels qu'ils eurent avec des gouverneurs et d'autres juges, ainsi que leurs disputes fréquentes avec les voisins à cause des actions qu'ils éxecutèrent en tant qu'administrateurs de justice et du gouvernement de la république.

Mots clés: Capitaines à Guerre, villes, villages, sites, gouvernement de la justice.

\section{Preliminares}

Los Capitanes a guerra fueron parte de la estructura institucional, jurídica y burocrática implantada por la corona española para gobernar y controlar sus posesiones en ultramar. En España estos funcionarios eran los jefes de los tercios de milicias alistados y repartidos en las provincias y lugares para 
su defensa y seguridad. Su título emanaba directamente del rey y llevaba anejo el de corregidor ${ }^{1}$.

En territorio americano, los corregidores eran funcionarios de base territorial local similar a los alcaldes mayores, pero a diferencia de estos se desempeñaban en dos modalidades: ordinario o de pueblos de españoles y de naturales o indígenas. Otro hecho fue la amplia jurisdicción desempeñada, la cual incluía corregimientos, partidos y municipios.

Las funciones encomendadas a estos funcionarios estaban recogidas en los Capitulos de Corregidores de 1500 y fueron revisadas en 1648, 1783 y 1788. Los capítulos u ordenanzas de 1500 constituyeron el primer compendio de normas reguladoras del cargo y de otros oficios ${ }^{2}$. Eran normativas provinciales y municipales que debían cumplir corregidores, gobernadores, alcaldes, alguaciles y, en general, todas las autoridades de las ciudades, villas y lugares de los reinos y señoríos de los monarcas católicos. Su propósito era garantizar la recta administración de justicia y el buen gobierno de las repúblicas municipales.

Por consiguiente, los Capitanes a guerra con título de corregidores desempeñaban sus funciones según lo establecido en esos capítulos u ordenanzas. Tenían, además, el carácter de magistrados con potestad de naturaleza jurídico-política delegada a su favor por el Rey. Esta circunstancia sería fuente de conflictos jurisdiccionales entre Capitanes a guerra y otros funcionarios como gobernadores, alcaldes mayores, regidores, alcaldes pedáneos e instituciones municipales como los cabildos y consulados de villas y ciudades. Los curas tampoco fueron ajenos a sus actuaciones y a las competencias jurídico-políticas que iban acumulando.

1 Félix Colón de Larriátegui, "Sobre el título de capitán á guerra". Félix Colón de Larriátegui, Juzgados militares de España y sus Indias, tomo I (París: en la Imprenta de C. Farcy, 1828), 196-202.

2 José de Bernardo Ares, "El régimen municipal en la Corona de Castilla", Studia Historica: Historia Moderna 15 (2015): 23-63, http://revistas.usal.es/index.php/Studia_Historica/article/view/2777; Gilberto Quintero Lugo, "El corregidor en la legislación indiana. El caso de los capítulos de los corregidores”, Procesos Históricos 26 (2014): 75-95. 
Las primeras actuaciones de los Capitanes a guerra en territorio americano estuvieron relacionadas con actividades militares en lugares habitados por indios hostiles. Luego también les fueron asignadas tareas militares en sitios de refugio de esclavos fugitivos, negros, zambos, mulatos y contrabandistas, en los cuales era denominador común un inestable control social y ausencia de autoridad y administración de justicia. En sus entradas a los territorios ocupados por los indios belicosos los Capitanes a guerra utilizaron presidios o fuertes como bastiones defensivos y cabezas de puente y contaron con la anuencia de los franciscanos, quienes establecieron misiones $^{3}$.

La historiografía colombiana sobre el gobierno hispánico ha prestado poca atención al tema de los Capitanes a guerra. Solo se han realizado menciones ligeras a estos funcionarios en trabajos cuya temática plantea problemas diferentes ${ }^{4}$. Solo Catalina Reyes ha realizado un intento serio por estudiar sus conflictivas actuaciones ${ }^{5}$.

El presente artículo examina las actuaciones de los Capitanes a guerra teniendo en cuenta el marco legal e institucional en el cual ellos surgieron y se legitimaron. Igualmente, como sus nombramientos en los gobiernos de algunas ciudades, villas, sitios y partidos del virreinato del Nuevo Reino de Granada estaban articulados a una política de Estado. Finalmente, los conflictos de jurisdicción que sostuvieron con gobernadores y otros jueces, y las disputas recurrentes con los vecinos por sus acciones como administradores de justicia y del gobierno de la república.

3 Alberto Gullón Abao, "La gobernación de Tucumán en la primera mitad del siglo XVIII. Coacciones y reacciones ante una guerra de frontera", Trocadero, 4 (1992): 72-84; José Alfredo Rangel Silva, Capitanes a Guerra, linajes de frontera. Ascenso y consolidación de las élites en el Oriente de San Luis, 1617-1823 (México El Colegio de México, 2008); Alberto Gullón Abao, La frontera del Chaco en la gobernación del Tucumán (1750-1810) (Cádiz, Universidad de Cádiz, 1993), 198-202.

4 María Teresa Arcila y Lucella Gómez, Libres, cimarrones y arrochelados en la frontera entre Antioquia y Cartagena. Siglo XVIII (Bogotá, Siglo del Hombre Editores-Iner-Universidad de Antioquia, 2009), 85-93; Marta Herrera Ángel, Ordenar para controlar. Ordenamiento espacial y control político en las llanuras del Caribe y en los Andes Centrales neogranadinos. Siglo XVIII (Bogotá, Icanh/ Academia Colombiana de Historia, 2002), 148-156.

5 Ana Catalina Reyes Cárdenas, "Corrupción, poder y abuso: el caso de los Capitanes a Guerra durante el tardío colonial en el Nuevo Reino de Granada”, Historelo Vol. 5 No. 9 (2013): 44-71. 


\section{LA RECONFIGURACIÓN DEL GOBIERNO ECONÓMICO Y POLÍTICO MUNI- CIPAL}

Uno de los tantos frentes en que incidió el reformismo borbónico fue el gobierno económico y político de algunas ciudades, villas, sitios y partidos del Nuevo Reino de Granada. A partir de 1740 se inició un proceso de reconfiguración territorial y jurisdicional de ciudades como Zaragoza, Remedios y Cáceres en la provincia de Antioquia; la de Simití y las villas de Ayapel, San Benito de Abad y Tolú en la provincia de Cartagena; la villa de Honda en la provincia de Mariquita y la de Tenerife en la provincia de Santa Marta, las cuales mostraban cuadros demográficos y fiscales deplorables. Esta situación contrastaba con el dinamismo poblacional y económico que reflejaban sitios de libres como Chiriguaná, Sitionuevo, Barranquilla, Real de la Cruz, Puerto Botijas, Santo Tomás de Villanueva, Lorica, Corozal, a los que luego se sumarían Magangué y Majagual.

La fórmula para mejorar el gobierno económico y político de esas ciudades y villas, luego extendida a la mayoría de los sitios de libres, incluía dos componentes. El primero, la reconfiguración de la vida municipal como mecanismo aglutinador y gestor de un nuevo poder. El segundo, el nombramiento de funcionarios con el título de Capitanes a guerra, corregidores y jueces de comisos. Estos funcionarios representaban el gobierno de la justicia y jugarían un papel importante como articuladores entre las poblaciones urbanas y las rurales. Su presencia fue preponderante en los puertos fluviales, barrancas, apostaderos y pequeños astilleros localizados en las proximidades de los ríos Magdalena, Cauca, San Jorge, Lebrija y Pamplona.

Estos funcionarios eran portadores de unas calidades que condensaban la autoridad y la justicia impartida en el mundo urbano y rural. Calidades, por demás, inherentes a los elementos que caracterizaban el régimen político hispánico. El primero de esos elementos era que en el sistema monárquico hispánico los empleos de república eran magistraturas y el número de oficiales designados debía ser proporcional al número de vecinos. Además, la obtención de un empleo estaba definido por un orden en el cual cada persona era tratada de acuerdo con su calidad y condición, es decir, de forma 
diferenciada, proporcionando a cada quien lo que le correspondía según el lugar que ocupaba en la sociedad ${ }^{6}$.

El segundo estaba relacionado con la justicia que en el orden hispánico presentaba un carácter jurisdiccional y funcionaba, en el sentido más estricto, como gobierno de la justicia, el cual era gobernado por el poder real sobre los espacios corporativos a través de figuras como los capitanes a guerra, corregidores, alcaldes mayores, pedáneos y partidarios y cabos de justicia. Esta representación corporativa unificada del reino que permitía situar el origen funcional del poder en el rey como cabeza de una república, no eliminaba la propia representación corporativa de cada uno de los espacios jurisdiccionales intermedios. Por el contrario, estos se hallaban fundidos bajo un agregado de sujetos, república de repúblicas municipales, reconocidas mutuamente a través de lazos recíprocos de lealtad, subordinación y obediencia derivados de la ordenación jerárquica de la sociedad. Esto permite comprender también la relativa menor incidencia de la acción real en las funciones relacionadas con la gestión de los intereses colectivos de cada cuerpo político naturalmente adscritos a sus esferas de autonomía, es decir, de una autotutela corporativa ${ }^{7}$.

El tercer elemento estaba relacionado con la forma como se administraba la justicia en el ámbito municipal, la cual estaba en manos de un oficial real que concentraba progresivamente la jurisdicción tradicional de los magistrados elegidos por las ciudades. La principal característica de este modelo fue que el ejercicio honorario de la jurisdicción estaba en manos de perso-

6 "Ley XVII, título 1"”, Las Leyes de Indias con las posteriores a este código vigente hoy y un epílogo sobre las reformas legislativas ultramarinas por Don Miguel de la Guardia, tomo IV (Madrid: Establecimiento Tipográfico de Pedro Núñez, 1889), 211-212; Hugues Sánchez Mejía, "De arrochelados a vecinos: reformismo borbónico e integración política en las gobernaciones de Santa Marta y Cartagena, Nuevo Reino de Granada, 1740-1810”, Revista de Indias Vol. LXXV 264 (2015): 457-487; Esaú Juvenal Ramírez Hernández, "Análisis de la categoría de calidad en la clasificación social de Nueva España (siglos XVII-XVIII)”, Históricas 97 (2013): 2-27; Katherine Bonil Gómez, Gobierno y calidad en el orden colonial (Bogotá: Universidad de los Andes, 2011), 1-22.

7 Alejandro Agüero, "Ciudad y poder político en el Antiguo Régimen. La tradición castellana", Cuadernos de Historia 15 (2005): 127-163; Carlos Garriga, "Sobre el gobierno de la justicia en Indias", Revista de Historia del Derecho 34 (2006): 67-160; Federica Morelli, "Entre el antiguo y el nuevo régimen: el triunfo de los cuerpos intermedios. El caso de la Audiencia de Quito", Historia y Política 10 (2003): 163-190. 
nas elegidas entre los naturales del lugar como era el caso de los alcaldes ordinarios. El modelo comenzó a reemplazarse por otro en el cual los jueces procedían de fuera de la comunidad y recibían un salario, es decir eran oficios rentados de designación real, que concentraban la jurisdicción local como fue el caso de los Capitanes a guerra y los corregidores. Ambos funcionarios constituirían la síntesis de un modelo de justicia regia de primera instancia que estaba a mitad de camino entre la imposición de un derecho común y de un derecho real. Ambos debían estar acompañados de un asesor letrado encargado de garantizar una administración de justicia basada en el conocimiento de los campos normativos, lo cual intentaba superar el antiguo ideal de juez lego con conocimiento del fuero y de la costumbre local. En conclusión, tanto Capitanes a guerra como Corregidores terminaban convertidos así en longa manu regis, llevando la justicia del rey al territorio ${ }^{8}$.

Muy importante es el cuarto elemento por cuanto después de la Paz de Utrecht la acción estatal entró en un proceso de ampliación administrativa y política acicateada por la creación de las Secretarías de Estado (Estado, Guerra, Justicia y Gracia y Marina e Indias) y el Despacho Universal de Indias, la introducción del sistema ejecutivo de gobierno que transfería los procedimientos jurídicos a la administración de justicia. El proceso estaba fundamentado en un proyecto irreversible de construir un Estado central con ideas novedosas cuyos poderes teóricos eran fuertes. En otras palabras, era una concepción del Estado organicista y organológica de la organización política que entendía esta como un cuerpo político que articulaba los intereses de todos sus miembros. Así, el gobierno era concebido como la cabeza y expresión última de la soberanía sobre el cuerpo?.

En los reinos hispánicos el desarrollo de ese ideal estatal enfrentó dos obs-

$8 \quad$ Federica Morelli, "Pueblos, alcaldes y municipios: la justicia local en el mundo hispánico entre Antiguo Régimen y Liberalismo”, Historia Crítica 36 (2008): 41-42.

9 Ernst H. Kantorowicz, Los dos cuerpos del rey. Un estudio de teología política medieval (Madrid: Alianza Editorial, 1985), 258; Paul Monod, "Estado, nación y monarquía en el siglo XVIII", en Las monarquías del Antiguo Régimen, ¿Monarquías compuestas?, dirs. Conrad Russel y José Andrés Gallego (Madrid: Editorial Complutense, 1996), 14; Quentín Skinner, "Una genealogía del Estado moderno", Estudios Políticos 118 (2010): 5-56; Horst Pietschmann, "El desarrollo estatal de Hispanoamérica: Enfoques metodológicos”, Chronica Nova 21 (1993-1994): 469-492. 
táculos. El primero, eran los privilegios y fueros, entre ellos el autonómico, del cual gozaban las comunidades políticas municipales y contra los cuales el Estado tenía que actuar. Esto originaba un mundo lleno de paradojas ya que el Estado con sus instituciones centralizadas, fiscales y administrativas, se proyectaba sobre unas bases cuestionadas por los mismos fueros de las comunidades que pugnaban por mantenerlos incólumes. Por lo tanto, a medida que el proceso avanzaba, las instituciones centralizadas daban muestras de un desgaste cada vez más notorio ${ }^{10}$.

Ahora bien, la única forma del Estado mantenerse y extender sus tentáculos sin contemplaciones para preservar su existencia y continuidad era estrechando vínculos con el monarca, lo cual remitiría al segundo problema. Las comunidades municipales con sus poderes y privilegios tendrían entonces por delante un gobierno central donde la cabeza era la figura del rey, pero acompañado de las Secretarías de Estado. Por el otro lado a los virreyes, audiencias y demás funcionarios quienes, en la mayoría de casos, se rotaban en los cargos y residían en América.

Estos cambios sociales y políticos afectarían las relaciones entre los poderes locales, intermedios y centrales rompiendo cualquier punto de equilibrio e inclinando la balanza a favor de uno o dos de ellos en detrimento de un tercero. Sin embargo, en el territorio americano el fenómeno no fue homogéneo. En las provincias del Nuevo Reino de Granada las reformas terminaron beneficiando a unos poderes locales más que a otros, por cuanto el sistema de gobierno económico y político terminó reconfigurándose en un esquema cuyo diseño estuvo dominado por las peculiaridades provinciales $^{11}$.

El punto de partida del proceso fue el proyecto modernizador de la monarquía hispánica iniciado en el tramo final del mandato de Felipe V quien, apoyado en el partido de Zenón de Somodevilla y Bengoechea, el marqués

10 Juan Luis Castellano Castellano, "Andalucía y el Estado en el siglo XVIII”, Chronica Nova 14 (198485): 71-91.

11 Horst Pietschmann, "Corrupción" en el virreinato novohispano: un tercer intento de valoración», e-Spania [En ligne], 16 | décembre 2013, mis en ligne le 19 décembre 2013, consulté le 03 juin 2016. URL: http://e-spania.revues.org/22848 ; DOI: 10.4000/espania/22848 
de la Ensenada, promocionó social y económicamente grupos emergentes provincianos vascos, riojanos, cántabros y navarros en detrimento de la élite castellana. De esos sectores surgieron los virreyes de Perú, Nueva España y Nuevo Reino de Granada, nombrando en este último al navarro Sebastián de Eslava ${ }^{12}$.

El virrey Eslava impulsó reformas tendientes a ordenar o corregir temas jurisdiccionales y territoriales, origen de choques serios con las realidades neogranadinas hasta ese momento existentes, pero que fueron instrumentalizadas durante su mandato para reforzar su autoridad frente a la metrópoli. No muy bien se había posesionado, cuando a finales de 1740 remitió un oficio a la Audiencia de Santa Fe señalando que mientras llegaban a sus "manos todas las nóminas de las Ciudades, Villas y Lugares, que no hacen elección para proveer en ellas los oficios de República correspondía, que la dirección debe ser a mí [el Virrey]"13. El oficio solo reafirmaba un saber y un poder transmitido a través de los consejos, advertencias e instrucciones reales recibidas por los virreyes, con los cuales ellos hacían las veces del rey y gobernaban en su nombre.

\section{LA ACCIÓN REFORMISTA SOBRE LA FIGURA DE LOS CAPITANES A GUERRA}

Entre 1741 y 1743 el virrey Sebastián de Eslava comenzó por definirles a los Capitanes a guerra las competencias en materia de justicia y gobierno. Sus acciones iniciaron por el río Cauca, en la provincia de Cartagena, en donde imperaba "el abandono y descuido en la cobranza de los tributos de indios” en perjuicio de la Real Hacienda. Entonces fundó el partido del Cauca nombrando corregidor y alcalde pedáneo a Jacinto Bustillo para el recaudo de los tributos de los ocho pueblos que lo integraban: Tacaloa, Yati, Magangué, Guazo, Panzegua, Jegua, Loba y Jagua. Luego, en un superior decreto estableció que los tributos cobrados serían entregados en

12 Víctor Peralta Ruiz, "Camaradas Políticos políticos y Paisanos. Amistad y clientelismo entre el virrey de Nueva Granada Sebastián Eslava y el marqués de la Ensenada (1741-1754)”, Nuevo Mundo Mundos Nuevos [En ligne], Colloques, mis en ligne le 09 janvier 2007, consulté le 24 février 2016. URL: http://nuevomundo.revues.org/3289 ; DOI:10.4000/nuevomundo.3289

13 José María Ots Capdequi, "El régimen municipal en el Nuevo Reino de Granada durante el siglo XVIII", Revista de la Universidad Nacional de Colombia 5 (1946): 93-94. 
las Cajas Reales del distrito por el mismo Bustillo, pero ahora con título de Capitán a guerra y Corregidor, posesión de jurisdicción ordinaria separada de la pedánea, posesionarse luego del pago de 50 pesos correspondientes a la media anata y dar fianza legas, nanas y abonadas a satisfacción de los oficiales reales ${ }^{14}$.

En la práctica la normativa del virrey Eslava se constituyó en "doctrina" citada en casos posteriores cuando algunos gobernadores, regidores o cabildos pretendieron desconocer o recortar la jurisdicción ordinaria de los Capitanes a guerra con título de corregidores. Por ejemplo, con base en ese precedente, un superior decreto del 22 de marzo de 1793 ordenaba que los Capitanes a guerra como jueces políticos respondían siempre a la necesidad, las especiales providencias obtenidas a su favor y la legítima costumbre ${ }^{15}$.

El virrey extendió su empresa reformista en esa materia por otros territorios de las provincias de Cartagena, Santa Marta, Antioquia y Mariquita. Intentaba así definir los ámbitos del gobierno económico y político de los Capitanes a guerra, quienes en años anteriores habían generado conflictos de jurisdicción con otras autoridades y funcionarios de mayor jerarquía.

En efecto, a finales del siglo XVII las actuaciones de los Capitanes a guerra ya habían originado una de las primeras disquisiciones casuísticas sobre el carácter y competencias de su magistratura. Luego de recorrer durante dos años los meandros del tribunal de la Real Audiencia, una real provisión de 1689 dispuso que los Capitanes a guerra no podían ejercer como jueces de apelaciones de la justicia ordinaria. Esta competencia solo correspondía al gobernador de la respectiva provincia o al teniente general letrado del gobierno y los "dichos capitanes a guerra en los lugares de su jurisdicción" solo estaban "para reconocer la gente de guerra" en las ocasiones que se presentaran ${ }^{16}$.

14 Archivo General de la Nación (en adelante AGN), Cabildos/ t. 8, f. 836.

16 AGN, Miscelánea/26, ff. 796v. 
El caso se dirimía en ese alto tribunal debido a que los Capitanes a guerra nombrados en las villas de Mompox y San Benito Abad en la provincia de Cartagena, investidos de ese título hacían "con la mano de la dicha jurisdicción ordinaria de jueces de apelaciones cuando ellos solo estaban para juntar la gente en lo que toca a lo militar [sin] actuar en casos civiles y criminales ni executivos en dicha instancia ni con ningún pretexto"17. El hecho de que la real provisión dispusiera que todo lo actuado por los Capitanes a guerra carecía de "valor ni exacto lo obrado todo lo que los dichos jueces de apelaciones así nombrados como los que se nombraren hubieren obrado y obraren" y fijara multas de hasta "trescientos pesos de buen oro", prisiones, secuestros y embargo de bienes para quienes incumplieran el mandato real era señal inequívoca de que la situación no solo había tomado "la forma y costumbre" que se guardaba en la época sino también que el poder de esos vasallos de la Corona era una realidad incuestionable ${ }^{18}$.

Empero, con el fin de aclarar dudas sobre el empleo de los Capitanes a guerra una nueva normativa real los ratificaba solo en "su cargo en lo tocante a guerra”. La Real Cédula de febrero 9 de 1696, publicada por Carlos II, restablecía las milicias en el Reino y a ellos se les confirmó la facultad que en el pasado tenían, concediéndoseles además, el fuero civil y criminal ${ }^{19}$.

Sin embargo, los problemas persistieron y a la vuelta del siglo las actuaciones de ellos empezaban a adquirir un carácter tan severo que en ocasiones originaban conflictos con corporaciones de mayor poder y raigambre. En 1708 el Maestre de Campo Miguel de Borda, en su condición de Comisario del Consulado de la Universidad de Cargadores del Nuevo Reino quien, además, tenía a su cargo la recaudación del real derecho de avería en la villa de Mompox iniciaba autos contra el Capitán a guerra de Simití por las repetidas quejas de los comerciantes que transitaban por el río de la Magdalena con destino a las provincias de Santa Fe, Popayán y Quibdó. La

19 Félix Colón de Larriátegui, Sobre el título de capitán, 197. 
principal acusación contra el Capitán a guerra era que este prácticamente había trasladado su lugar de residencia al sitio de Canaletal, distante de la ciudad de Simití cinco días río arriba. Desde ese sitio y apoyado en cuatro subalternos, quienes portaban armas de fuego, el Capitán a guerra realizaba registros y decomisos de mercaderías luego de abrir con su machete las $\operatorname{cargas}^{20}$.

En la práctica, el Capitán a guerra había trasladado su residencia al sitio mientras su presencia en Simití era ocasional. Esto originaba quejas entre los vecinos por cuanto afirmaban que su desidia era tan notoria y pública que tenía la ciudad en el mayor abandono.

Nuevas disposiciones reales eran emitidas para definir el estatus de estos funcionarios en el interior del cuerpo armado. El Reglamento de Milicias de 1704 fue complementado con la Real Ordenanza de 31 de enero de 1734. Ambas normativas definieron a las milicias como una institución regular con carácter general mientras la Real Ordenanza estableció que las milicias provinciales quedaban bajo el mando y sujeta su jurisdicción en primera instancia a los Capitanes a guerra. Sin embargo, estas disposiciones problematizaron la delimitación territorial y el precepto constitutivo del fuero sobre el derecho que tenía una comunidad política a hacer la guerra bajo sus propios mandos y jefes naturales como cabezas de la colectividad designados por sus instituciones corporativas. En este contexto, el Capitán a guerra, investido del título y cargo de corregidor con competencia tanto en asuntos civiles como militares, terminaba convertido en un funcionario algo extraño y de una "bisible repugnancia" como lo manifestaban los vecinos notables de la comunidad política guipuzcoana estudiada por Lourdes Soria Sesé21.

En tales circunstancias se decretaron nuevas normativas tendientes a definir las jurisdicciones de cuerpos militares y civiles. Los reglamentos iniciales fueron adicionados con otras disposiciones como la del 28 de febrero

20 AGN, Consulados/1, ff. 245-254.

21 Lourdes Soria Sesé, "La defensa militar en el ordenamiento jurídico foral: preceptos constitutivos y actividad reglamentaria durante los siglos XVIII y XIX”, Iura Vasconiae 4 (2007): 327-365. 
de 1736 y la real declaración de 30 de mayo de 1767 con las cuales se les concedió a los coroneles la privativa jurisdicción sobre todas las causas con inhibición de cualesquiera jueces, justicias, tribunales, e incluso, de los jefes militares de la provincia. La estocada final al carácter militar de los Capitanes a guerra la proporcionó la real orden de 13 de febrero de 1786 la cual establecía que los corregidores o alcaldes mayores no necesitaban del título de Capitán a guerra para conocer de sus causas y quedaban sujetos al gobernador, o a su teniente con total dependencia del Capitán General ${ }^{22}$.

En los territorios americanos los Capitanes a guerra siguieron un peculiar derrotero aún con la aplicación de las disposiciones reales sobre las milicias. La Real Cédula del 4 de abril de 1783 y las disposiciones de 1788 resultan claves para entender la adaptación de esos funcionarios en el gobierno económico y político de algunos territorios del Virreinato del Nuevo Reino de Granada. Las disposiciones contenían en detalle las competencias gubernativas, judiciales, financiero-hacendísticas y de defensa de esos funcionarios verdaderos alter ego del rey por antonomasia en el nivel local ${ }^{23}$.

En particular, la reforma de 1783 convirtió a los Capitanes a guerra en agentes que impulsarían la consolidación de instituciones municipales ya que ellos eran parte de un poder local preponderante en el interior del engranaje burocrático hispánico. Convirtieron sus actuaciones públicas, la forma de administrar justicia y el ejercicio del buen gobierno en temas candentes que obligaban a la intervención de justicias superiores.

Por ejemplo, el visitador general de las provincias de Santa Marta y Río del Hacha y de la villa de Santa Cruz de Mompós, don Manuel Antonio Rubianes, luego de realizar el "mejor arreglo de los capitanes a guerra y los jueces de ellas" señalaba que la mayor parte de su vida estaba dedicada a los

22 Félix Colón de Larriátegui, Sobre el título de capitán, 198.

23 Real Cédula de S. M. y señores del Consejo, por la cual se establecen las reglas y providencias que deben observarse en lo sucesivo para el modo de proveerse y servirse los Corregimientos y Alcaldías Mayores de los Reynos de Castilla y Aragón, é Islas adyacentes. Madrid, Imprenta de don Pedro Marín. Año 1783, http:/ / catalog.hathitrust.org/Record/009299199. Consulta en línea 11 de abril de 2014. 
estudios y "útilmente en servicios del Rey y del Estado"24. Sin embargo, la forma como llevó a cabo su visita y las relaciones amistosas que entabló con esos funcionarios terminaría reduciendo el Estado a un poder central lejano que aparentaba ser temible de cerca, pero que paradójicamente al final transaba con las peculiaridades provinciales y locales.

En medio de la constitución de un Estado centralizador fuerte y la intrincada red de poderes locales y provinciales, en el Nuevo Reino de Granada la figura de los Capitanes a guerra en el gobierno económico y política de ciudades, villas, sitios y partidos fue considerada la más adecuada. Sin embargo, sus funciones se limitaban a temas de gobierno y justica, y el adjetivo "de guerra" solo mantuvo una tradición inane que en varias ocasiones tuvo que ser aclarada porque "los capitanes a guerra no gozan en el día ni aun en esta línea de facultades [militares] ni en España ni en América por el diverso pie en que se han puesto las milicias de ambos dominios"25.

Por consiguiente, estos funcionarios fueron estatuidos para garantizar una recta administración de justicia y el recaudo de los bienes reales en el ramo de alcabalas, minas, tributos de indios, el celo y la vigilancia de la Real Hacienda de tratos ilícitos, fraude y contrabando. Ello explica por qué la amplitud del título de su nombramiento como Capitanes a guerra, corregidores, justicias mayores y jueces de comisos se mantenía y ayuda a comprender sus actuaciones con el desempeño simultáneo como gobernantes y jueces de un sistema de justicia jurisdiccional y policéntrico que generaba conflictos.

Desde su doble condición de administradores y jueces sus acciones influyeron y afectaron la vida e intereses corporativos de las comunidades políticas para las cuales su sistema de valores estaba en buena medida fundamentada en la costumbre. En resumen, fueron otra pieza más del gobierno de la justicia que caracterizaba al régimen político de la monarquía hispánica.

24 AGN, Residencias Magdalena-Bolívar-Tolima-Venezuela/64, f. 48.

25 AGN, Competencias-Bolívar y Panamá/2, f. 302v. 


\section{Títulos y QUerellas JURISDiccionales}

En la segunda mitad del siglo XVIII, los Capitanes a guerra se habían impuesto como figuras de un modelo de justicia real que debían cumplir las normas relativas a su nombramiento. La primera, la postulación a la vacante del cargo era realizada por vencimiento del periodo, fallecimiento del titular o mediante solicitud hecha por un tercero. Segunda, la solicitud estaba acompañada de la relación de méritos del aspirante, demostrar no ser deudor de la Real Hacienda y contar con una persona acreedora de la fianza de residencia. Tercera, una vez realizado el nombramiento estaban obligados a pagar la media anata, un descuento realizado a los empleados y funcionarios reales correspondiente a la mitad del sueldo de un año de trabajo. Finalmente, debían prestar el juramento de rigor y próximos a concluir su periodo, someterse al escrutinio oficial de los juicios de residencia, requisito suprimido por Real Cédula de finales del siglo XVIII.

Las funciones de los Capitanes a guerra estaban en consonancia con la amplitud propia expresada en el título del nombramiento y de la importancia del lugar adonde iban a gobernar. Con el establecimiento del virreinato del Nuevo Reino de Granada, a partir de 1740 serían nombrados por el virrey, representante del monarca en estos dominios, confiriéndoseles el carácter de justicias mayores y el de oficiales de la Real Hacienda y, aunque existían instrucciones, capítulos y ordenanzas al momento de ejercer sus funciones debían actuar de acuerdo con su propio nombramiento y a la costumbre del lugar ${ }^{26}$.

La presentación de algunos casos ayuda a la comprensión del tema. Por ejemplo, don Ignacio Sánchez de Mora fue nombrado Capitán a guerra, justicia mayor y corregidor de naturales del partido de Magangué por un periodo de cinco años con el mismo sueldo, obvenciones, facultades y jurisdicción de sus antecesores. Estaba obligado al "afianzamiento de los reales intereses que fueran de su cargo recaudar" como único juez territorial e independiente del partido, el cual "obtuvo con obrepción", y era

26 María del Refugio González y Teresa Lozano, "El alcalde mayor o el corregidor como jueces", Revista de la Facultad de Derecho de México 142-143-144 (1985): 567. 
asistido de un teniente protector de indios. La cabeza del partido era el sitio de Nuestra Señora de la Candelaria de Magangué, en donde también residía un teniente diputado del comercio, y su jurisdicción comprendía seis sitios y los pueblos de indios de Talaigua, Yati, Guazo y sus anexos ${ }^{27}$.

La capitanía a guerra de Sánchez de Mora fue uno de los casos que registró un enfrentamiento vehemente entre dos poderes con orígenes diferentes: el de los regidores de la villa de Mompox de carácter honorario ejercido por personas elegidas entre los vecinos del lugar y el de los Capitanes a guerra, funcionarios ajenos a la comunidad con designación real, salario y jurisdicción ordinaria como únicos jueces territoriales de un partido.

En 1801, los capitulares de Mompox intentaron imponer al capitán a guerra Sánchez de Mora la restricción de su jurisdicción ordinaria solo en los pueblos de naturales mientras en los sitios de blancos y gente libre debía proceder con jurisdicción pedánea. La normativa ya había sido impuesta a sus antecesores Cosme Bermúdez y Diego Palacio, quienes elevaron quejas ante el gobierno de la ciudad de Cartagena con resultados infructuosos. La disposición de los regidores estaba fundamentada en el desconocimiento del modelo de justicia real y la antigua costumbre de que dichos sitios, antes de la creación de las capitanías a guerra, eran gobernados por los Alcaldes de la Santa Hermandad. Estos funcionarios ejercían la jurisdicción ordinaria que de manera irregular le delegaban los alcaldes de la villa de Mompox $^{28}$.

El cabildo de Mompox mantuvo su posición para que entendiera "el agraciado en el uso y manejo de la administración de justicia”. El capitán Sánchez de Mora respondió con un escrito sobre el significado de su título librado "por la superioridad del virrey del Reino" y haberse posesionado sin necesidad de fianza de residencia "por hallarse extinguido este juicio por novísima real cédula” del 24 de agosto de 1799. Los regidores le insistieron sobre la obligación que tenía de administrar justicia por separado a

27 AGN, Virreyes/11, ff. 233-234; Competencias-Bolívar y Panamá/2, ff. 288-290.

28 AGN, Cabildos/8, f. 862. 
las personas según sus calidades o linaje, lo cual habían aceptado los anteriores Capitanes a guerra ${ }^{29}$.

Entonces, el Capitán a guerra Sánchez de Mora interpuso acciones judiciales ante los tribunales superiores del reino. Para el efecto nombró como su apoderado al procurador de número don Luis de Ovalle quien presentó varios memoriales, pedimentos y petitorios acompañados de declaraciones de algunos vecinos y documentos sobre títulos de Capitanes a guerra dictados desde "tiempo inmemorial". Con base en ellos el procurador señalaba al cabildo de Mompox de usurpador de facultades por cuanto la disputa se dirimía “en dos palabras": el corregimiento y la capitanía a guerra. Además, si ellas estaban acompañadas con la denominación de justicia mayor, la cual estaba desde "tiempos muy remotos en la pacífica e inalterable posesión de la jurisdicción ordinaria”, entonces la justicia impartida por los Capitanes a guerra no podía ser pedánea sobre los blancos y gente libre y ordinaria con respecto a los naturales. Los argumentos del procurador fueron concluyentes con relación a que la jurisdicción ordinaria era ejercida sobre las poblaciones del partido y la "escandalosa temeridad del congreso de Mompox" chocaban contra tres fundamentos: la costumbre, las particulares providencias y la necesidad pública, los cuales estaban consolidados desde los tiempos del virrey Sebastián de Eslava ${ }^{30}$.

El dictamen de los tribunales terminó reconociendo la autoridad de Mora ya que los Capitanes a guerra acompañados del título de corregidores "son y han sido los únicos jueces territoriales de todo el partido" 31 . Aunque el cabildo de Mompox decidió acatar la providencia consideró que el Capitán a guerra Sánchez de Mora no debía gozar de la razón de ese empleo propia de "aquellos ministros de justicia que preocupados de una ciega ambición de mando, intentan señorearse con las despreciables ideas del orgullo, y de la ostentación" 32 . La conducta de ambos actores, regidores y Capitán a guerra, trascendía los argumentos jurídicos de la querella ya que estaban en juego el control sobre los tributos de los indios de los pueblos

32 AGN, Cabildos/8, f. 857. 
mencionados y el recaudo de los bienes reales de su majestad en los sitios del partido de Magangué.

Las competencias de los Capitanes a guerra en materia hacendística era una de las que generaba mayores querellas jurisdiccionales. A fin de cuentas se trataba del recaudo de los bienes del erario real. En ocasiones las querellas judiciales fueron acaloradas cuando ellos eran nombrados en el gobierno económico y político de una ciudad que mantenía la presencia de los alcaldes ordinarios, los regidores, el cabildo y otros magistrados propios de su jerarquía urbana. Entre 1787 y 1790 el Capitán a guerra y oficial real de la ciudad de Zaragoza, don Hilario Antonio de Robles sostuvo un pleito contra el juez de diezmos secular y eclesiástico, don Manuel Urbina, ya que una vez posesionado, se le presentó con el título de juez de diezmos eclesiástico y secular librado por la Junta General de Diezmos de Santa Fe con el fin de que lo reconociera como tal. Urbina le aclaraba, además, que el título lo convertía en recaudador único de los reales novenos con la competencia de remitirlos al juez general para que ingresaran directamente en las Reales Cajas de Santa Fe. El Capitán a guerra argumentaba que entre sus competencias estaba la de recaudador de los bienes de la Real Hacienda y no podía quedar reducido a asistir a los remates como "convidado de piedra". Al final, Robles aceptó la situación con el fin de evitar un enfrentamiento de mayores dimensiones con los regidores y el cabildo de Zaragoza que expresaban absoluta confianza en Urbina ${ }^{33}$.

Una situación diferente se presentó en el sitio de Santa Catalina de Turbaco en donde el cura doctrinero y párroco del pueblo solicitaba al virrey Antonio Amar y Borbón, dictar un superior decreto que ordenara y mandara la cobranza de sus primicias, estipendios y derechos de obvenciones, tanto a los naturales como a los vecinos, solo al juez real Capitán a guerra Pablo Velásquez. El cura justificaba su solicitud por las "intendencias de su capitanía", porque los deudores defraudaban los derechos reales y él no tenía con qué sustentarse ${ }^{34}$.

34 AGN, Diezmos/10, f. 960. 
Un escenario donde se enfrentaron dos poderes con características similares fue la capitanía a guerra del sitio de Barranca de Rey. El sitio era un puerto fluvial cercano a la ciudad de Cartagena custodiado por un destacamento militar acantonado en el vecino puerto de Barranca La Vieja. El principal empleo fue ejercido en varios periodos por Pablo José Torregrosa, quien en 1786 como capitán a guerra, juez ordinario y de comisos de Barranca del Rey solicitaba al virrey Manuel Antonio Flores suprimir esa comandancia y dejar bajo su mando solo siete hombres de tropa con los cuales se ahorraría el erario real los salarios que demandaba sostener un oficial, el sargento, seis soldados, dos artilleros y un tambor. Aunque la solicitud de Torregrosa tuvo oposición en el interior del mismo gobierno se dispuso concederle la gracia basada en argumentos similares a lo practicado en el partido de Barranquilla donde se suprimió el destacamento militar apostado en el puerto marítimo de Sabanilla disponiéndose que los Capitanes a guerra como jueces de comisos estaban obligados "a celar por su parte cuanto entra y sale por aquellas inmediaciones" 35 .

Siete años después las pretensiones de Torregrosa fueron mayores. En 1793 mediante instancia hecha al rey solicitaba que en remuneración del mérito, comisiones importantes y servicios contraídos por espacio de 16 años en el sitio de Barranca del Rey se le perpetuase la capitanía a guerra con el título de corregimiento y un sueldo mayor. En su petitorio señalaba las intenciones del gobernador de Cartagena, Anastasio Zejudo de separarlo del cargo para el cual ya tenía hasta candidato. Aunque se mantuvo en suspenso la solicitud de conferirle carácter vitalicio a su empleo, desde Madrid la Secretaría de Estado prevenía al virrey del Nuevo Reino de Granada de no permitir la remoción del Capitán a guerra Torregrosa "ni se haga con él la menor novedad, si no ocurriesen causas graves y extraordinarias para ejecutarlo hasta que su Majestad tome resolución sobre sus pretensiones $^{36}$.

A finales del siglo XVIII no existían dudas sobre la importancia de los Capitanes a guerra como hombres del rey en "el remedio de los males" del

36 AGN, Empleados Públicos de Bolívar/25, f. 895. 
gobierno económico y político de ciudades, villas y sitios. Así lo consideró el oidor visitador de la provincia de Antioquia Juan Antonio Mon y Velarde luego de practicar la visita a los pueblos de San Antonio del Peñol, San Antonio de Pereira, la ciudad de Rionegro y sitio de Marinilla. Durante su vista encontró que el Capitán a guerra con jurisdicción sobre los valles de Rionegro, Llanogrande y Marinilla había desatendido por razón de la distancia la administración de justicia en el último de ellos. Aunque podía parecer benéfico incorporar el sitio de Marinilla y Rionegro con el fin de estimular a los vecinos en sus elecciones de empleos concejiles la reciente erección de la segunda en ciudad y la pretensión que tenía el sitio en ser elevado a villa hacía que los habitantes de "de una y otra parte" se miraran "con particular emulación que toca en desafecto". Por lo tanto, lo más plausible era nombrar en el sitio de Marinilla y su jurisdicción un Capitán a guerra con jurisdicción ordinaria con el fin de evitar mayores perjuicios a la recta administración de justicia. El visitador concluía la presentación de su proyecto proponiendo para el cargo a don Isidro Peláez, alcalde partidario del mismo sitio ${ }^{37}$.

También hubo casos en que los mismos vecinos elevaban representación ante las instancias superiores para que se les nombrara un Capitán a guerra. En 1759, los vecinos de la villa solicitaron al gobernador de Cartagena les nombrara un Capitán a guerra, justicia mayor y juez de cobranzas reales y de comisos. Ellos argumentaba que "la inopia de sujetos idóneos que hay en dicha villa de Ayapel, su pobreza para obtener los empleos de República, y el riesgo, que corre de la real hacienda administrada por ellos" conduciría a declarar la extinción de los alcaldes ordinarios ${ }^{38}$. La solicitud no tuvo curso alguno ya que el gobernador no poseía las competencias jurisdiccionales para nombrar esa clase de funcionarios y el asunto fue trasladado al virrey para que dictara la providencia correspondiente.

El empleo lo obtuvo Joseph Francisco de Nájera, persona que acreditaba haber sido alcalde ordinario de Zaragoza, administrador de la Real Hacienda y "afianzar a satisfacción de los oficiales reales de la de Mompox satis-

37 AGN, Vistas Antioquia/2, ff. 1070-1073.

38 AGN, Residencias Bolívar/26, f. 884v. 
facer el real derecho de media anata, y cumplir con los demás requisitos necesarios". La conclusión del juicio de residencia acreditó que el Capitán a guerra había observado buena conducta y arreglado las Cajas Reales con celo.

\section{Lo NOCIVO QUE ERA EL QUE VINIESEN AQUí SUJETOS FORASTEROS DE Capitanes a Guerra}

Mientras en los sitios de libres la transición hacia un gobierno económico y político a la cabeza del cual estaban los Capitanes a guerra fue en sus inicios imperturbable, en las ciudades y villas la llegada de estos funcionarios constituyó una fuente de conflictos. El nombramiento de un Capitán a guerra con las calidades de Joseph de Nájera, pero que procedía de fuera podía generar enfrentamiento y alineamiento de los vecinos en "partidos".

En 1793 parte del vecindario de Ayapel organizó un motín contra Felipe Acosta, titular del empleo de Capitán a guerra, justicia mayor, juez ordinario y de comisos, alcalde mayor de minas, y teniente oficial real ${ }^{39}$. Los amotinados estaban dirigidos por Francisco Codezo y Gerónimo Zaragoza, quienes hacían parte de los "caracterizados" notables de la villa. Al momento del motín, Codezo era teniente de Capitán a guerra y mayordomo de la fábrica de la iglesia del Santísimo Cristo, cargo en el cual llevaba doce años. Zaragoza era tratante y propietario de varios hatos de ganado en las cercanías del río San Jorge. A ellos se les sumaba Rafael Gómez, hijo del anterior Capitán a guerra de la villa, quien había ejercido "las funciones de tal en calidad de teniente", cuando su padre Faustino Lorenzo Gómez, principal motor de la sublevación, se ausentaba del empleo. Muchos testigos fueron obligados a declarar ante el alcalde ordinario de la Villa de San Benito ante presión de Codezo y Zaragoza quienes en una carta "los estrechaban a que comparecieran allí ante el capitán a guerra Toribio de Mier multándolos con 25 pesos si no obedecían, a nombre del virrey"40.

La mayoría de los testigos tenían "parentesco espiritual” con Codezo y

39 AGN, Visitas Bolívar/7, ff. 889-930.

40 AGN, Visitas Bolívar/7, f. 891. 
Zaragoza, y según los calificativos de un grupo de vecinos todos eran unos pobres miserables que no tenían camisa qué ponerse y de "inferior calidad”. Fernando Mejía, de color zambo medio oficial de zapatería, era más un "zapatero remendón” fámulo de la casa de don Pedro Martínez de Pinillos, vecino de Mompox y concuñado de Codezo; Pedro de Hoyos de oficio boga; Bernardo de Torres trabajaba para Codezo en el retablo de la Iglesia; Tiburcio Cortinas, un "pobre mestizo" de oficio herrero, "embrollón en todos sus tratos" era "un triste indio e infeliz" sin camisa que ponerse y tenía el "defecto de quedarse con el dinero que le dan anticipadamente cuando le mandan a hacer alguna obra, por lo cual está reprobado por muy tramposo, y embustero". Los hermanos Custodio y Diego García, el primero boga y el segundo labrador y matador de ganado; su hermana Dolores era manceba de Rafael Gómez; finalmente calificaron a Tiburcia Cadrasco, como una zamba manceba de Zaragoza ${ }^{41}$.

Lo primero que hicieron los amotinados fue otorgar poder al procurador de número de la ciudad de Santa Fe, Joseph Antonio Maldonado. En su memorial el procurador señaló que los vecinos querían que los siguiera gobernando y administrando justicia sujetos nombrados entre la comunidad por "lo nocivo que era el que viniesen aquí sujetos forasteros de Capitanes a Guerra"

Un grupo de vecinos, opuesto a los amotinados, denunció el poder otorgado a Maldonado como "falsamente autorizado" ya que no había sido firmado por los sujetos más característicos en la República como lo eran don Juan Joseph García y don Andrés Troncoso, testigos presentes de actuación; don Pantaleón de Esqueda considerado "un hombre republicano" en esta villa pues había obtenido el empleo de Teniente de Capitán a guerra; don Anastasio Quintero que fue Alcalde de la Santa Hermandad "en tiempo que hubo aquí cabildo"; don Juan de Dios Delgado, y otros "sujetos acomodados que aquí hay" como Agustín Mascaron, Juan de la

41 AGN, Visitas Bolívar/7, ff. 891v-896.

42 AGN, Visitas Bolívar/7, f. 899. 
Rosa Benítez, Diego Araújo, Juan Aldana, Simón Zabaleta, Simón de los Santos, Mateo Polo, y otros "que son los que públicamente prestan la voz de un Pueblo"'43.

Este caso evidencia el impacto del nuevo sistema de empleos que permitía a personas que estaban por fuera de la comunidad política ocupar cargos. Pero revela la llegada a estos empleos de algunos elementos de origen étnico distinto: mulatos, pardos o zambos. Aunque, al final, no dejó de ser conflictiva la relación entre Capitanes a guerra con esa calidad y los vecinos como fue el caso del sitio de Mahates en 1808 cuyos habitantes eran en su mayoría negros libres, mulatos y zambos.

A mediados de ese año, Roque Grajales, en representación suya y del vecindario del sitio, escribió una representación al virrey para que negara la solicitud de la Capitanía a guerra hecha por Rafael Martelo. La exposición de motivos para que la solicitud fuera negada relacionaba los antecedentes del solicitante: la práctica continua del engaño para obtener sus negocios, la opresión y exacciones que acostumbraba ejecutar en los vecinos, la prisión a que los reducía sin causa alguna y su calidad: hijo natural, "que lo hubo de una negra" con Paulo Martelo, este sí un vecino honrado del sitio. Por lo tanto, Rafael Martelo era inhábil para un cargo que siempre había recaído en "personas de sangre limpia y legítimo nacimiento", pero además carecía de "principios de educación, y de policía [civilidad y urbanidad]" 4 .

A lo anterior se sumaba que era vecino de la plaza de Cartagena y siempre que gobernaba se entregaba a otros zambos y mulatos como sus confidentes y "directores aún en los asuntos judiciales". De hecho, Rafael Martelo ya había ejercido entre 1804 y 1806 la capitanía a guerra de Mahates y los engaños en que, según los vecinos, tenía sumido al virrey eran inexistentes. Lo cierto era que él contaba con la confianza del gobierno de Cartagena que lo había encargado de varias comisiones en otros lugares de la pro-

43 AGN, Visitas Bolívar/7, f. 906.

44 AGN, Empleados Públicos de Bolívar/25, f. 571. 
vincia como la que persiguió y aprehendió al "reo de Estado" Juan José Solano, yerno de Agustín Núñez Nieto, Capitán a guerra del sitio de Barranca ${ }^{45}$.

El malestar de los vecinos iba más allá de la calidad mulato de Martelo, no solo porque era de fuera sino también porque tenía la "protección" del teniente de gobernador de Cartagena, José Munive, "un tal Ayos José Antonio] abogado de alli’” y un coronel de milicias. Por esa razón le solicitaban al virrey no realizar el nombramiento de Martelo y así se evitarían "malas consecuencias" para el vecindario que "aburrido de padecer lo harán perecer al golpe de una bala o los filos de un machete". La explosiva y filosa advertencia también estaba dirigida contra el otro aspirante a la Capitanía a guerra del sitio, Fernando de Cos, quien intentaba repetir en el cargo, pero su mala conducta era notoria en la ciudad de Cartagena ${ }^{46}$.

\section{TrES CONCLUSIONES PRELIMINARES PARA CONTINUAR}

La primera, el reformismo borbónico mantuvo la figura de los Capitanes a guerra provenientes del régimen político de los Austrias. En el nuevo modelo Borbón los Capitanes a guerra adquirieron una organización civil que fue integrada a la maquinaria burocrática decidida a ser lo más eficiente en el plano de la administración de justicia y de las finanzas.

La segunda, las actuaciones de los Capitanes a guerra generaban disputas que permitían salir a la luz hechos que normalmente permanecían ocultos. En sí, ellas despertaban los recuerdos de los vecinos y los conducían a la evocación y al examen de los precedentes.

La tercera: la característica distributiva de la administración de justicia influyó en la consolidación de una cultura de la queja y el reclamo en todas las esferas de la sociedad con la defensa del bien común de la república. Los casos individuales de conflictos entre personas o grupos constituye la mejor evidencia del surgimiento de unos nuevos sistemas de valores.

45 AGN, Juicios Criminales/204, f. 776.

46 AGN, Empleados Públicos de Bolívar/25, f. 572. 


\section{Bibliografía}

\section{Fuentes Primarias}

Archivo General de la Nación (AGN). Aduanas (Tomo 2), Cabildos (Tomo 8), Competencias-Bolívar y Panamá (Tomo 2), Consulados (Tomo 1), Diezmos (Tomo 10), Empleados Públicos de Bolívar (Tomo 25), Juicios Criminales (Tomo 204), Miscelánea (Tomo 26), Residencias Magdalena-Bolívar-Tolima-Venezuela (Tomo 64), Virreyes (Tomo 1), Visitas Antioquia (Tomo 7), Visitas Bolívar (Tomo 26).

Las Leyes de Indias con las posteriores a este código vigente hoy y un epílogo sobre las reformas legislativas ultramarinas por Don Miguel de la Guardia, tomo IV, Madrid: Establecimiento Tipográfico de Pedro Núñez, 1889.

Real Cédula de S. M. y señores del Consejo, por la cual se establecen las reglas y providencias que deben observarse en lo sucesivo para el modo de proveerse y servirse los Corregimientos y Alcaldías Mayores de los Reynos de Castilla y Aragón, é Islas adyacentes. Madrid, Imprenta de don Pedro Marín. Año 1783. http:/ / catalog.hathitrust. org/Record/009299199. Consultada el 22 de junio de 2015.

\section{Fuentes Secundarias}

Agüero, Alejandro. "Ciudad y poder político en el Antiguo Régimen. La tradición castellana”. Cuadernos de Historia 15 (2005): 127-163.

Ardila, María Teresa, y Lucella Gómez. Libres, cimarrones y arrochelados en la frontera entre Antioquia y Cartagena. Siglo XVIII. Bogotá: Siglo del Hombre-Iner-Universidad de Antioquia, 2009.

Bernardo Ares, José Manuel de. "El régimen municipal en la Corona de Castilla”. Studia Historica: Historia Moderna 15 (2015): 23-63. http:// revistas.usal.es/index.php/Studia_Historica/article/view/2777

Bonil Gómez, Katherine. Gobierno y calidad en el orden colonial. Bogotá: Universidad de los Andes, 2011.

Castellano Castellano, Juan Luis. "Andalucía y el Estado en el siglo XVIII”. Chronica Nova 14 (1984-85): 71-91.

Colón de Larriátegui, Félix. Juzgados militares de España y sus Indias, Tomo I. París: en la Imprenta de C. Farcy, 1828. 
Garriga, Carlos. "Sobre el gobierno de la justicia en Indias". Revista de Historia del Derecho 34 (2006): 67-160;

González, María del Refugio, y Teresa Lozano. "El alcalde mayor o el corregidor como jueces”. Revista de la Facultad de Derecho de México 142-143-144 (1985): 565-580.

Gullón Abao, Alberto. La frontera del Chaco en la gobernación del Tucumán (1750-1810). Cádiz: Universidad de Cádiz, 1993.

Gullón Abao, Alberto. “La gobernación de Tucumán en la primera mitad del siglo XVIII. Coacciones y reacciones ante una guerra de frontera". Trocadero 4 (1992): 71-84.

Herrera Ángel, Marta. Ordenar para controlar. Ordenamiento espacial y control político en las llanuras del Caribe y en los Andes Centrales neogranadinos. Siglo XVIII. Bogotá: Icanh-Academia Colombiana de Historia, 2002.

Kantorowicz, Ernst H. Los dos cuerpos del rey. Un estudio de teología política medieval. Madrid: Alianza, 1985.

Monod, Paul. "Estado, nación y monarquía en el siglo XVIII". En Las monarquías del Antiguo Régimen, ¿Monarquías compuestas?, dirs. Conrad Russel y José Andrés Gallego. Madrid: Complutense, 1996, 11-29.

Morelli, Federica. "Entre el antiguo y el nuevo régimen: el triunfo de los cuerpos intermedios. El caso de la Audiencia de Quito". Historia y Política 10 (2003): 163-190.

Morelli, Federica. "Pueblos, alcaldes y municipios: la justicia local en el mundo hispánico entre Antiguo Régimen y Liberalismo". Historia Crítica 36 (2008): 36-57.

Ots Capdequi, José María. "El régimen municipal en el Nuevo Reino de Granada durante el siglo XVIII". Revista de la Universidad Nacional de Colombia 5 (1946): 75-111.

Peralta Ruiz, Víctor. «Camaradas políticos y paisanos. Amistad y clientelismo entre el virrey de Nueva Granada Sebastián Eslava y el marqués de la Ensenada (1741-1754)». Nuevo Mundo Mundos Nuevos [En ligne], Colloques, mis en ligne le 09 janvier 2007, consulté le 24 février 2016. URL: http://nuevomundo.revues.org/3289; DOI:10.4000/ nuevomundo.3289

Pietschmann, Horst. «"Corrupción” en el virreinato novohispano: un tercer intento de valoración», e-Spania [En ligne], 16 | décembre 2013, 
mis en ligne le 19 décembre 2013, consulté le 03 juin 2016. URL:http:/ / e-spania.revues.org/22848; DOI: 10.4000/espania/22848

Pietschmann, Horst. "El desarrollo estatal de Hispanoamérica: Enfoques metodológicos". Chronica Nova 21 (1993-1994): 469-492.

Quintero Lugo, Gilberto. "El corregidor en la legislación indiana. El caso de los capítulos de los corregidores”. Procesos Históricos 26 (2014): 75-95.

Ramírez Hernández, Esaú Juvenal. "Análisis de la categoría de calidad en la clasificación social de Nueva España (siglos XVII-XVIII)”. Históricas 97 (2013): 2-27.

Rangel Silva, José Alfredo. Capitanes a Guerra, linajes de frontera. Ascenso y consolidación de las élites en el Oriente de San Luis, 1617-1823. México: El Colegio de México, 2008.

Reyes Cárdenas, Ana Catalina. “Corrupción, poder y abuso: el caso de los

Capitanes a Guerra durante el tardío colonial en el Nuevo Reino de Granada”. Historelo Vol. 5 No. 9 (2013): 44-71.

Sánchez Mejía, Hugues. "De arrochelados a vecinos: reformismo borbónico e integración política en las gobernaciones de Santa Marta y Cartagena, Nuevo Reino de Granada, 1740-1810”. Revista de Indias Vol. LXXV No. 264 (2015): 457-487.

Skinner, Quentín. “Una genealogía del Estado moderno”. Estudios Políticos 118 (2010): 5-56.

Soria Sesé, Lourdes. "La defensa militar en el ordenamiento jurídico foral: preceptos constitutivos y actividad reglamentaria durante los siglos XVIII y XIX”. Iura Vasconiae 4 (2007): 327-365.

Para citar este artículo: Conde Calderón, Jorge. "Capitanes a guerra: 182 Gobierno económico y político en el Virreinato del Nuevo Reino de Granada", Historia Caribe Vol. XI No. 29 (Julio-Diciembre 2016): 155-182. DOI: http://dx.doi.org/10.15648/hc.29.2016.7 